DOI https://doi.org/10.30525/978-9934-588-81-5-1.20

\title{
СТАН ПРОБЛЕМИ ФІЗИЧНОЇ ТЕРАПІЇ У СИСТЕМІ ЛІКУВАННЯ ГОСТРОЇ ХІРУРГІЧНОЇ ПАТОЛОГІЇ ОРГАНІВ ЧЕРЕВНОЇ ПОРОЖНИНИ
}

\author{
Гула Г. В. \\ кандидат медичних наук, \\ дочент кафедри фізичної терапії та ерготерапії \\ Львівський державний університет фізичної культури \\ імені Івана Боберського \\ м. Львів, Украӥна
}

Гостра хірургічна патологія органів черевної порожнини (ГХП ОЧП) безумовно становить одну із актуальних проблем сучасних наукових досліджень та практичної медицини $[1,2,13]$. Частота ГХП ОЧП залишається значною, а результати ії лікування, незважаючи на поступове впровадження сучасних діагностично-лікувальних методів, потребують подальшого покращення $[2,6,9,11]$. ГХП ОЧП є найбільшою за обсягом групою загальнохірургічних захворювань, лікування яких вимагає значних організаційних, професійних та фінансових ресурсів [2, 3, 10]. Хірургічне лікування, проблемноорієнтоване і засноване на доказах, потребує відвертої обгрунтованої оцінки та базується на концепції належної якості досліджень, які на сьогодні у ряді випадків є недостатніми $[9,12,14]$. На підставі таких досліджень сформовано клінічні стандарти/протоколи надання медичної допомоги при ГХП ОЧП $[4,11,14]$. Водночас, проблема ФТ у лікуванні ГХП ОЧП залишається невирішеною, а наявний науковопрактичний матеріал недостатньо імплементований у стандарти системи охорони здоров'я $[10,15]$.

Зв'язок роботи з науковими програмами, планами, темами. Робота $€$ фрагментом НДР Львівського державного університету фізичної культури «Фізична терапія при хірургічних захворюваннях», № держ. реєстрації 0120U100962.

Мета дослідження - окреслити стан розв'язання проблеми ФТ у системі лікуванні ГХП ОЧП.

Матеріали і методи дослідження: аналіз літератури, чинних нормативних актів, які регулюють надання медичної допомоги та ФТ при ГХП ОЧП. 
Результати дослідження та їх обговорення. Визначальними чинниками впливу на результати лікування ГХП ОЧП є: суттєві патогенетичні зміни в організмі, спричинені характером основного захворювання i його ускладненнями, які у разі несвоєчасного та неповноцінного лікування призводять до прогресуючої поліорганної недостатності; необхідність екстреного оперативного втручання; значна летальність, особливо за поєднаної супутньої патології, також - у похилому та старечому віці $[3,14,15]$.

Окремі етапи лікування ГХП ОЧП здійснюють відповідно до положень медико-технологічних документів зі стандартизації медичної допомоги, із використанням алгоритмів діагностично-лікувальної допомоги $[1,2,5]$. Хірургічні втручання при ГХП ОЧП виконують невідкладно, за абсолютними показаннями. У випадку наростання тяжкості загального стану, порушення вітальних функцій організму, поліорганної дисфункції (> 10 балів за АРАCHE II; прогнозована летальність > 15\%) і високого операційного ризику (3-4 ст. за CEPOD; 3-4 ст. за ASA) першочерговим $є$ проведення інтенсивної терапії та, в ряді випадків, хірургічного втручання за життєвими показаннями $[2,8]$. Післяопераційне лікування проводять у відділенні інтенсивної терапії до стабілізації вітальних функцій (із наступним переведенням до хірургічного відділення) [2, 12]. Профілактиці тромбоемболічних ускладнень, нутриційній підтримці, післяопераційному знеболенню при ГПХ ОЧП приділено значну увагу, деталізовано принципи та алгоритми їх застосування $[4,10,13]$. Водночас, застосування ФТ у протоколі стаціонарного лікування ГХП ОЧП практично не згадується. Ранню активізацію хворих та методи фізичного впливу (ЛФК, пасивна флексія стоп, масаж; еластична компресія нижніх кінцівок, переміжна пневмокомпресія) вказують серед неспецифічних заходів профілактики тромбозу. Лише у рекомендаціях при виписці серед бажаних заходів побіжно зазначають реабілітацію, збереження адекватного режиму праці, обмеженість важкої праці, фізіотерапевтичне лікування та ЛФК $[2,4,6]$.

ГХП ОЧП в результаті вивільнення медіаторів запалення, больового синдрому, підвищеної стомлюваності, зменшення маси тіла та зниження легеневої функції спонукає до ліжкового режиму та мінімальної рухомості [8]. Окремі праці свідчать про необхідність проведення ранньої ФТ як невід'ємної складової лікувального процесу після оперативного лікування ГХП ОЧП, поряд із інтенсивною та медикаментозною терапією $[5,7]$. Забезпечення ФТ при ГПХ ОЧП є компетенцією спеціалістів з ФТ та реабілітації. Примірну посадову інструкцію та 
кваліфікаційні характеристики лікаря ЛФК затверджує наказ МО3 України від 29.03.2011p. № $176[10,11,15]$. Ряд досліджень засвідчили позитивний вплив ФТ на результати лікування ГХП ОЧП (загальна та післяопераційна летальність, післяопераційні, легеневі та серцеві ускладнення, тривалість стаціонарного лікування тощо) $[10,15]$. Водночас, наявні докази рандомізованих досліджень залишаються слабкими через відсутність злагодженої системи ФТ при ГХП ОЧП, що обмежує оцінку результатів $[4,6]$.

Сучасні дослідження пропонують поняття «Протоколу посиленого післяопераційного відновлення» (Enhanced Recovery After Surgery (ERAS) Protocol), що становить собою мультидисциплінарну програмy, покликану мінімізувати реакцію на хірургічне лікування та сприяти відновленню функцій організму. Модель ERAS інтегрує ряд елементів періопераційної допомоги в стандартизований клінічний шлях для хірургічних пацієнтів [12]. Вказана програма ERAS зокрема засвідчила суттєвий позитивний вплив на результати лікування при невідкладній колоректальній хірургії: зменшила післяопераційні ускладнення, скоротила тривалість перебування в лікарні та знизила економічні витрати [11]. Окремі оглядові дослідження вказують на зростаючий інтерес та значення застосування ФТ у плановій хірургії, яка однак не включена до протоколів ERAS. Поряд із цим, результати досліджень та клінічних випробувань $\epsilon$ суперечливими, й остаточних висновків не отримано [12].

Висновки та перспективи подальших досліджень. Таким чином, результати аналізу наукових праць та діючих діагностичнолікувальних протоколів беззаперечно засвідчують, що проблема ФТ як інтегрованої складової системи комплексного лікування ГХП ОЧП не $\epsilon$ розв'язаною, а наявний теоретичний матеріал та практичний досвід не імплементований у систему охорони здоров'я України. Цілий ряд аспектів потребує подальшого дослідження з метою концептуального синтезу клінічного значення ФТ у комплексному протоколі лікування ГХП ОЧП.

\section{Література:}

1. Березницький Я.С, Ярошенко К.О. Сучасні організаційні та тактичні питання лікування шлунково-кишкових кровотеч. Acta medica Leopoliensia. 2015. T. 21, № 3. C. 73-77.

2. Фомін П.Д. Невідкладна хірургія органів черевної порожнини (стандарти організації та професійно орієнтовані алгоритми надання 
медичної допомоги) / за ред. П.Д. Фоміна, О.Ю. Усенка, Я.С. Березницького. Київ: Бібліотека «Здоров’я України», 2018. 354 с.

3. Al-Temimi M.H., Griffee M., Enniss T.M. et al. When is death inevitable after emergency laparotomy? Analysis of the American College of Surgeons National Surgical Quality Improvement Program database. J Am Coll Surg. 2012. Vol. 215, N. 4. P. 503-511.

4. Barberan-Garcia A., Ubré M., Roca J. et al. Personalised prehabilitation in high-risk patients undergoing elective major abdominal surgery: a randomized blinded controlled trial. Ann Surg. 2018. Vol. 267, N. 1. P. 50-56.

5. Boden I., Sullivan K., Hackett C. et al. ICEAGE (Incidence of Complications following Emergency Abdominal surgery: Get Exercising): study protocol of a pragmatic, multicentre, randomised controlled trial testing physiotherapy for the prevention of complications and improved physical recovery after emergency abdominal surgery. World J Emerg Surg. 2018. Vol. 13, N. 7. P. 29.

6. Gramlich L.M., Sheppard C.E., Wasylak T. et al. Implementation of enhanced recovery after surgery: a strategy to transform surgical care across a health system. Implement Sci. 2017. Vol. 67, N. 12. P. 1-17.

7. Hajibandeh S., Hajibandeh S., Bill V. et al. Meta-analysis of Enhanced Recovery After Surgery (ERAS) Protocols in Emergency Abdominal Surgery. World J Surg. 2020. Vol. 44, N. 5. P. 1336-1348.

8. Havey R., Herriman E., O'Brien D. et al. Guarding the gut: early mobility after abdominal surgery. Crit Care Nurs Q. 2013. Vol. 36, N.1. P. 63-72.

9. Howes T.E., Cook T.M., Corrigan L.J. et al. Postoperative morbidity survey, mortality and length of stay following emergency laparotomy. Anaesthesia. 2015. Vol. 70, N. 9. P. 1020-1027.

10. Kamarajah S.K., Bundred J., Weblin J. et al. Critical appraisal on the impact of preoperative rehabilitation and outcomes after major abdominal and cardiothoracic surgery: A systematic review and metaanalysis. Surgery. 2020. Vol. 167, N. 3 - P. 540-549.

11. Ljungqvist O., Scott M., Fearon K.C. Enhanced recovery after surgery: a review. JAMA Surg. 2017. Vol. 152, N. 3. P. 292-298.

12. Orange S.T., Northgraves M.J., Marshall P. et al. Exercise prehabilitation in elective intra-cavity surgery: A role within the ERAS pathway? A narrative review. Int J Surg. 2018. Vol. 56, N. 8. P. 328-333.

13. Rose J., Weiser T.G., Hider P. et al. Estimated need for surgery worldwide based on prevalence of diseases: a modelling strategy for the 
WHO Global Health Estimate. Lancet Glob Health. 2015. Vol. 27, N. 3. P. 13-20.

14. Tengberg L.T., Bay-Nielsen M., AHA study group et al. Multidisciplinary perioperative protocol in patients undergoing acute high-risk abdominal surgery. Br J Surg. 2017. Vol. 104, N. 4 - P. 463-471.

15. Visioni A., Shah R., Gabriel E. et al. Enhanced recovery after surgery for noncolorectal surgery? A systematic review and meta-analysis of major abdominal surgery. Ann Surg. 2018. Vol. 267, N. 1. P. 57-65.

DOI https://doi.org/10.30525/978-9934-588-81-5-1.21

\title{
ОЦІКА ВМІСТУ АНТИМІКРОБНОГО ПЕПТИДУ КАТЕЛЦЦИИНУ LL-37 ТА ГІДРОКСИХОЛЕКАЛЬЦИФЕРОЛУ В СИРОВАТЦІ КРОВІ ДІТЕЙ, ХВОРИХ НА МУКОВІСЦИДОЗ, ЗАЛЕЖНО ВІД ФУНКЦІї ЗОВНІШНЬОГО ДИХАННЯ
}

\begin{abstract}
Дудник В. М.
доктор медичних наук, професор, завідувач кафедри педіатрії № 2

Вінницький національний медичний університет імені М. І. Пирогова

Демянишина В. В.

аспірант кафедри педіатрії № 2

Вінницький національний медичний університет імені М. І. Пирогова м. Вінниця, Украӥна

Прогресуюче ураження легень $\epsilon$ найчастішою причиною високої летальності муковісцидозу (МВ) серед дітей. Проведення функціональних тестів для визначення тяжкості легеневих проявів хвороби грає важливу роль у клінічній оцінці пацієнта, адже допомагає вчасно виявити відхилення у функції легень. Спірометрія, зокрема показник ОФВ1 та ФЖЄЛ, найбільш широко використовуваний метод моніторингу хвороби легень при МВ. Порушення нормального показника об’єму форсованого видиху (ОФВ1) вважається предиктором смертності та рекомендований як первинний клінічний критерій оцінки респіраторної функції [4]. Визначення ступеня відхилення ОФВ1 протягом всього періоду розвитку захворювання дозволяє краще розуміти розвиток захворювання легень, а також дозволяє ідентифікувати фак-
\end{abstract}

